Research Article

\title{
Development and Characterization of Enclosed Prochlorperazine Maleate Floating Alginate Beads
}

\author{
Suraj B. Pund ${ }^{1 *}$, Vishwas C. Bhagat ${ }^{2}$, Madhuri T. Deshmukh ${ }^{3}$, Rajkumar V. Shete ${ }^{4}$ \\ ${ }^{1}$ Research Scholar Department of Pharmaceutics, Rajgad Dnyanpeeth's College of Pharmacy, Bhor, Pune, Maharashtra, India. \\ 2Department of Pharmaceutical Chemistry Rajgad Dnyanpeeth's College of Pharmacy, Bhor. Dist- Pune. India. \\ ${ }^{3}$ Department of Pharmaceutics Rajgad Dnyanpeeth's College of Pharmacy, Bhor. Dist- Pune, India. \\ ${ }^{4}$ Department of Pharmacology, Principal of Rajgad Dnyanpeeth's college of Pharmacy, Bhor. Dist- Pune, India.
} *Corresponding author's E-mail: surajpund143@gmail.com

Received: 14-03-2021; Revised: 22-05-2021; Accepted: 30-05-2021; Published on: 15-06-2021.

\section{ABSTRACT}

The objective of present study aims to formulate enclosed floating alginate beads of Prochlorperazine Maleate (PCZM) for the treatment of nausea and vomiting. The Prochlorperazine Maleate which is having lower bioavailability up to $12.5 \%$ and also, it's a lower biological half-life so which required multiple dosing frequencies 3-4 times a day. Bioavailability refers that to extend and rate at which the active moiety enters into the systemic circulation to the site of action. Biological half-life is the time that a body requires to eliminate one-half the quantity of an administered substance. So, by using Floating Alginate Beads of Prochlorperazine maleate which is help to Produced sustained released action up to 12 hours. Hence, it helpful for improvement of bioavailability and biological half-life, and reduced frequency of dosing. The Prochlorperazine Maleate (PCZM) beads were formulated by the lonotropic gelation method by sodium alginate solution containing Low methylated pectin in various ratios. The Preformulation study was performed like Physical characters, Drug Excipients compatibility study by Calibration curve, FTIR and DSC study. The floating alginate beads were evaluated by different parameters like Percentage yield, Drug Content (DC) \& Entrapment Efficiency (EE), In-vitro Drug Release study, particle size analysis, Z-Potential, SEM, PXRD, Stability study. The result of the FT-IR and DSC study indicated the stability and compatibility of the drug \& polymers. The standard calibration curve in $0.1 \mathrm{~N} \mathrm{HCl}(\mathrm{pH} 1.2)$ showed a regression of 0.999 . The percentage yield was found to be $86.29 \%$ to $95.90 \%$. The drug content was found to be $3.7-4.7 \mathrm{mg}$. The percentage buoyancy was found to be $89.40 \%$ to $97.50 \%$. The in-vitro drug release study of the formulated batch was ranged from $77.29 \%$ to $91.44 \%$ at the end of $12 \mathrm{~h}$. The best formulation was selected as batch B-2 which gives the best result based on Percentage Yield, DC, EE, buoyancy study, and In-vitro Drug Released study. Particle size observed in Nano range that is $393.3 \mathrm{~nm}$ and, Z-potential found to be $-2.84 \mathrm{mV}$. By Scanning Electron Microscopy (SEM) the beads were shown to be Spherical and slightly rough surface because of drying. A powdered $X$-Ray Diffraction study showed that the drug is converted from crystalline to an amorphous form. The B 2 Optimized batch drug content was found to be $4.62 \mathrm{mg}$ and it is having no change in its physical appearance. Hence it shows good stability up to 60 th day.

Keywords: Prochlorperazine maleate, Sodium alginate, Pectin, Floating drug delivery, lonotropic gelation.

QUICK RESPONSE CODE $\rightarrow$

DOI:

10.47583/ijpsrr.2021.v68i02.027

DOI link: http://dx.doi.org/10.47583/ijpsrr.2021.v68i02.027

\section{INTRODUCTION}

T

he objective of the drug delivery system is to deliver a therapeutic amount of drugs to the right place in the body to quickly reach them and maintain the proper desired concentration of drugs. The oral route increases progressively when used for the delivery of therapeutic agents due to the low compensation of the therapy and the ease of administration leading to get more patients satisfaction. Near about $50 \%$ or more drugs are in the oral drug delivery system available in the market. ${ }^{1-3}$ Conventional (commercial) oral dosage forms offer no control over drug delivery, leading to fluctuations in the plasma drug concentration levels. These have the difficulty of releasing all or nothing from the emptying process, although the multi-unit particle system passes through the GIT to evade the vagaries of gastric emptying and thus release the drug more consistently. Numerous approaches have been developed to increase the retention of an oral dosage form in the stomach. for example, floating systems, expansion-by-expansion systems, muco-adhesive systems, and high-density systems. ${ }^{4-6}$

Floating multiparticulate gastroretentive drug delivery systems based on effervescent and non-effervescent approaches. Hollow microspheres are, empty spherical particles without the nucleus in a severe sense, this alginate are typically free-flowing powders consisting of synthetic proteins or polymers, which are ideally spherical beads of approximately $2.5 \mathrm{~mm}$ diameter. ${ }^{5-6}$ Microparticles are different spherical microcapsules that function as the solid substrate on which the drug is layered or encapsulated in the bead's core. Beads can provide controlled release properties and the bioavailability of pearl formulated drugs can also be improved. Floating alginate beads achieves the goal of developing a gastroretentive drug delivery system is to maintain the drug's release action, as well as to improve the therapeutic effect 
of the dosage form into the stomach or gastric media until all of the drugs is completely released in the desired period. These multiparticulate dosage forms have several advantages over single-unit preparations, including immutable dispersion in the gastrointestinal tract (GIT), invariable drug absorption, reduced inter-and intraindividual variability, avoid possibilities of dose discharge, improving flow property, and are more flexible formulation processes..$^{5-6}$

\section{Definition}

Floating drug delivery systems are low-density systems that have suitable buoyancy to float overhead the gastric contents and continue to float in the stomach without disturbing the rate of gastric emptying for an extended time. $^{8}$

This result is longer gastric retention time and good control of fluctuations in plasma drug concentration. Many floating systems treated in granules, powders, capsules, tablets, laminated films, and sacred microspheres, alginate beads have been developed. ${ }^{9}$

\section{MATERIALS AND METHODS}

Prochlorperazine Maleate Gift sample from Harika Drugs PVT. LTD Hyderabad. Sodium Alginate Pallavi Chemicals and Private Ltd, Andheri Mumbai. Pectin Pallavi Chemicals and Private Ltd, Andheri Mumbai. Calcium Chloride Research Lab Fine Chem Industries, Mumbai.

\section{Formulation and Development}

Table 1: Formulation Table for Prochlorperazine maleate loaded floating beads

\begin{tabular}{|c|c|c|c|c|}
\hline $\begin{array}{c}\text { Formulation } \\
\text { code }\end{array}$ & $\begin{array}{c}\text { Prochlorperazine } \\
\text { maleate } \mathbf{( m g )}\end{array}$ & $\begin{array}{c}\text { Sodium Alginate } \\
\mathbf{( m g )}\end{array}$ & $\begin{array}{c}\text { Pectin (Low } \\
\text { Methylated) (mg) }\end{array}$ & $\begin{array}{c}\text { Calcium Chloride } \\
\text { (\%) }\end{array}$ \\
\hline B-1 & 200 & 1 & 0.5 & 5 \\
\hline B-2 & 200 & 1 & 1 & 5 \\
\hline B-3 & 200 & 1.5. & 0.5 & 5 \\
\hline B-4 & 200 & 1.5 & 1 & 5 \\
\hline B-5 & 200 & 1 & 0.5 & 10 \\
\hline B-6 & 200 & 1 & 1 & 10 \\
\hline B-7 & 200 & 1.5 & 0.5 & 10 \\
\hline B-8 & 200 & 1.5 & 1 & 10 \\
\hline
\end{tabular}

\section{Methods}

Formulation and Characterization of Beads will be prepared by the Ionotropic gelation method. ${ }^{10-11}$

\section{Preparation of Floating beads by lonotropic Gelation Method}

All ingredients were weighed properly according to the formula. Then weighed quantity of Pectin was dissolved in the water and kept aside for at least $1 \mathrm{~h}$. Then sodium alginate was dissolved in $50 \mathrm{ml}$ of water to form a uniform paste solution. After $1 \mathrm{~h}$ when pectin solution was formed properly. The prepared pectin solution added into the sodium alginate paste with continuous stirring up to get the uniform paste of required consistency. To this prepared uniform paste, Prochlorperazine maleate was added with continuous stirring and this mixture get ultrasonicate for 15 minutes to remove air bubbles. Then Calcium chloride solution $5 \%$ (5g in $100 \mathrm{ml}$ water) and $10 \%$ (10g in $100 \mathrm{ml}$ water) was kept on a magnetic stirrer for continuous stirring. For the preparation of floating beads, Drug + polymer solution was added dropwise into calcium chloride solution through the syringe with the needle of 24 gauges with 300 RPM. This complete solution allowed standing for $1 \mathrm{~h}$ for curing. Then prepared floating beads were filtered with Whatman filter paper, washed it 2 to 3 time with water and air-dried at room temperature or hot air oven up to $25^{\circ} \mathrm{C}$ for $48 \mathrm{hr}$. and stored in plastic sealable bags.

Flow Chart for Formulation of Prochlorperazine Maleate Floating Beads

Sodium Alginate + Distilled Water

$\downarrow$ dissolved

Pectin + Distilled Water

$\downarrow$ dissolved (kept aside for at least $1 \mathrm{~h}$ )

Sodium Alginate + Pectin (mix with continuous Stirring up to uniform paste)

\section{$\downarrow$}

Drug Dispersed into Polymeric solution by continuous stirring

$\downarrow$

Added dropwise through 24 Gauze needle under calcium chloride solution with magnetic stirring Crosslinking solution

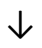


Beads were formulated (Filter, wash with water and airdried at room temperature or hot air oven up to $25^{\circ} \mathrm{C}$ for $48 \mathrm{hr}$ )

\section{Preformulation Studies}

The Preformulation studies are conducted to establish the physicochemical characteristics of the drug and its compatibility with the various excipients. The Preformulation studies are necessary to formulate drugs into stable, safe, and effective dosage form.

\section{* Colour \\ * Nature \\ * Odour}

Physical State: ${ }^{12-13}$

\section{Melting point}

A small amount of drug powder was placed into a fusion tube. That tube is set in the melting point determining apparatus containing liquid paraffin. The temperature of the drug put in a capillary was gradually increased mechanically and read the temperature at which powder started to melt up to all powder gets melted and temperature is calculated by the thermometer. ${ }^{14}$

\section{Drug Solubility}

Drug solubility studies of Prochlorperazine maleate were achieved threefold by adding required amounts of the drug to water and buffer solutions having different $\mathrm{pH}$ (4.5) buffers. The solutions containing flasks were kept on a rotary shaker for $24 \mathrm{~h}$. After $24 \mathrm{~h}$, solutions were determined by using UV spectrophotometer at $256 \mathrm{~nm}$, which was the maximum absorption analyzed prematurely and drug concentrations were calculated.

\section{Drug excipient compatibility study}

The drug and excipients are chosen for the formulation were screened for compatibility by physical methods and Fourier Transform Infrared (FTIR) spectroscopic studies. ${ }^{15}$

\section{Compatibility Study by FTIR}

Infrared spectroscopy can be used to determine a compound and also to investigate the composition of the mixture. Pure drugs, polymers, excipients, and drug excipient mixture were subjected to FTIR studies to investigate the Drug- excipient interactions. The IR spectra of the test samples were obtained by the Pressed Pellet Technique using Potassium bromide. ${ }^{16}$

\section{Potassium Bromide Pellet Method}

A minor quantity of finely ground solid samples intimately mixed with about 100 times its weight of powdered potassium bromide. The finely ground mixture was then passed under very high pressure in a press (at least 25,000 psig) to form a small pellet (about 1-2 $\mathrm{mm}$ thick and $1 \mathrm{~cm}$ in diameter). The resulting pellet was transparent to IR radiation and was run as such.

\section{Differential Scanning Calorimetry (DSC)}

The DSC studies were carried out to observe the thermal behavior of drug-loaded Beads whether the drug was encapsulated in them or not. The DSC analysis of pure drug, polymers, and the physical mixture of drug and polymers were carried out using a differential scanning calorimeter (METTLER TOLEDO). The Sample of $5 \mathrm{mg}$ was placed in a $50 \mu \mathrm{l}$ perforated aluminum pan and sealed. Heat runs for each sample were set from $5^{\circ} \mathrm{C}$ to $300^{\circ} \mathrm{C}$ using nitrogen as purging gas and samples were analyzed. ${ }^{16}$

\section{Calibration Curve Preparation}

\section{Preparation of Buffer Solutions}

\section{Preparation of $0.1 \mathrm{~N}(1.2 \mathrm{pH})$ Hydrochloric Acid}

$8.5 \mathrm{ml}$ of the hydrochloric acid was dissolved in distilled water and made up to $1000 \mathrm{ml}$ to get $0.1 \mathrm{~N}$ hydrochloric acid. $^{17}$

\section{Preparation of Calibration Curve for Prochlorperazine Maleate}

$100 \mathrm{mg}$ of Prochlorperazine maleate drug was transferred to $100 \mathrm{ml}$ of volumetric flask and made up to volume with $0.1 \mathrm{~N} \mathrm{HCL} .10 \mathrm{ml}$ was pipetted out into a separate $100 \mathrm{ml}$ flask and made up to volume with $0.1 \mathrm{~N} \mathrm{HCL}$. $5 \mathrm{ml}, 10 \mathrm{ml}$, $15 \mathrm{ml}, 20 \mathrm{ml}, 25 \mathrm{ml}$ and $30 \mathrm{ml}$ were taken and made up to $100 \mathrm{ml}$ using $0.1 \mathrm{~N} \mathrm{HCL}$. The absorbance of the resulting solutions was measured at $256 \mathrm{~nm}$ using a UV spectrophotometer. The calibration curve was plotted concentration versus Absorbance. ${ }^{18-19}$

\section{Flow property measurements}

The flow properties of powers/beads are critical for an efficient Capsule filling operation. A good flow of the sample to be filled is necessary to assure efficient mixing and acceptable weight uniformity for the filled capsule. The flow property measurements include bulk density, tapped density, angle of repose, compressibility index, and Hausner's ratio. The flow property measurements of the beads were determined. ${ }^{17}$

\section{Angle of Repose}

The angle of repose benefits to evaluate powder flowability by assessing inters particulate friction. In general, the higher the angle of repose gives poor flowability of the powder. The angle of repose of each powder blend was determined by the glass funnel method. And it is calculated used by the following equation as follows, ${ }^{20}$

$\tan \theta=h / r$

$\theta=\tan ^{-1}(h / r)$

Where, $\theta=$ Angle of repose,

$h=$ Height of the pile,

$r=$ Radius of the cone made by powder blend. 


\section{Tapped Density}

The Tapped density aids to determine packing geometry and flowability. The Tapped density is the volume of powder was determined by tapping 100 using a measuring cylinder having a weighed amount of sample. Tapped density is calculated by the following equation, [20]

$$
\text { Where, } \begin{aligned}
\rho t & =\mathrm{M} / \mathrm{Vt} \\
\rho t & =\text { Tapped density. } \\
\mathrm{M} & =\text { Weight of the powder. } \\
V t & =\text { Tapped volume. }
\end{aligned}
$$

\section{Bulk Density}

Bulk density is the ratio of mass to bulk volume. It may impact the dissolution and other properties and depends on the particle size, shape, and tendency of particles to hold together. The cylinder was dropped three times from a height of one inch for the rest of two seconds. The bulk density is calculated by the following equation, 20

$$
\rho b=M / V b
$$

Where,

$$
\begin{aligned}
& \rho b=\text { Bulk density } \\
& M=\text { Weight of the powder, } \\
& V b=\text { Bulk volume. }
\end{aligned}
$$

\section{Hausner's Ratio}

The lower Hausner's ratio indicates good flow properties. As well as the greater ratio indicates poor flow property. Hausner's ratio can be calculated by formula, 20

$$
\text { Hausner's ration }=\frac{\text { Tap Density }}{\text { Bulk Density }}
$$

\section{Carr's Index:}

Carr's index is an important property for maintaining uniform weight. Carr's index is calculated using the formula, 20

$$
\begin{aligned}
& \text { Carr's Index }=\frac{\text { Tapped Density }- \text { Bulk density }}{\text { Tapped density }} \times 100 \\
& \begin{array}{l}
\text { Characterization } \quad \text { Parameters of } \\
\text { Prochlorperazine Maleate Floating Beads }
\end{array}
\end{aligned}
$$

\section{Percentage Yield}

The prepared sample is to collect and weigh accurately. The measured weight separated by the total amount of non-volatile material that is used in the formulation gives the percentage yield. Percentage yield is calculated by the following formula, ${ }^{21}$

Percentage Yield $=\frac{\text { Actual weight of product }}{\text { Total weight of drug and Polymers }} \times 100$

\section{Drug Content}

$100 \mathrm{mg}$ equivalent drug-loaded polymer beads will be dissolved in a suitable solvent. It will be stirred using a magnetic stirrer. The resulting solution will be then filtered and the filtrate will be suitably diluted with a suitable solvent. Drug content can be determined spectrophotometrically by the single-point method. ${ }^{22}$

$$
\text { Drug content }=\frac{\mathrm{A} \text { test } \times C \text { std })}{A \text { std }}
$$

Where. $A_{\text {test }}$ is Absorbance of test

$\mathrm{C}_{\text {std }}$ is the Concentration of standard

A test is Absorbance of standard.

\section{Drug Entrapment Efficiency ${ }^{23}$}

$$
\text { Entrapment Efficiency }=\frac{\text { Actual } \text { Yield }}{\text { therotical Yield }} \times 100
$$

\section{In vitro buoyancy study}

Alginate beads (300mg) were scattered over the USP XXIV dissolution apparatus type II containing $900 \mathrm{ml}$ of $0.1 \mathrm{~N} \mathrm{HCl}$ and $0.02 \%$ Tween 80 . The medium was disturbed with a paddle revolving at $100 \mathrm{rpm}$ for $12 \mathrm{hr}$. The floating and the immersed portions of particles were collected separately. The microparticles were dehydrated and weighed. The Buoyancy percentage is measured as the ratio of the mass of the particles that remained buoyant and the total mass/weight of the particles. ${ }^{23-25}$

$$
\% \text { Buoyancy }=\frac{Q F}{Q F+Q S}
$$

Where,

$$
\begin{aligned}
& Q F=\text { Weight of the floating Beads } \\
& Q s=\text { Weight of settled Beads }
\end{aligned}
$$

\section{In-vitro drug release study}

The drug release analysis of alginate beads is conducted by using USP dissolution apparatus Type II containing $900 \mathrm{ml}$ of $0.1 \mathrm{~N} \mathrm{HCl}$ as dissolution media $(\mathrm{pH}-1.2)$ at $100 \mathrm{rpm}$ and $37^{\circ} \mathrm{C}$. Then a $10 \mathrm{ml}$ sample was taken at $1 \mathrm{hr}$. the time interval for $12 \mathrm{hr}$. and at the same volume of fresh medium replaced to maintain sink condition. Taken samples were assayed spectrophotometrically at a suitable wavelength. The drug release was analyzed by UV spectrophotometer. ${ }^{26-28}$

\section{Particle Size analysis}

The Particle Size analysis of the drug-loaded beads of Prochlorperazine Maleate was measured on a Zeta dip tube (Malvern Instrument V.2.3) at a scattering angle of $90^{\circ}$. A sample $(0.5 \mathrm{mg})$ of the floating alginate beads suspended in $5 \mathrm{~mL}$ of distilled water was used for the measurement. Each reading was made in triplicate. ${ }^{29}$

\section{Determination of Zeta potential}

The Zeta potential of the drug-loaded beads of Prochlorperazine Maleate was measured on a Zeta dip tube (Malvern Instrument V.2.3) by determining the 
electrophoretic mobility in a micro electrophoresis flow cell. All the samples were measured in water at $25^{\circ} \mathrm{C}$. Each reading was made in triplicate. ${ }^{29}$

\section{Scanning Electron Microscopy (SEM)}

Morphological examination of the surface and internal structure of the dried beads can be performed by using a scanning electron microscope. ${ }^{30,31}$

\section{P-XRD Analysis}

XRD Analysis carried out due to study the nature of drug used in a formulation. By the XRD analysis, the amorphous or crystalline nature of the drug can find out. And preparation for the final formulation the drug nature remains as it is for that the XRD comes in a Preformulation studied. ${ }^{16}$

\section{Stability studies}

Stability is defined as the extent to which a product remains within specified limits throughout its period of storage and use. A drug formulation is said to be stable if it fulfills the following requirements. ${ }^{32}$

1. It should contain at least $90 \%$ of the stated active ingredient.

2. It should contain an effective concentration of added preservatives if any

3. It should neither exhibit discoloration or precipitation nor develops a foul odor.

4. It should not develop irritation or toxicity.

\section{Procedure}

The formulation was divided into 2 sets of samples and stored at Room Temperature (30 으) $40 \circ \mathrm{C} \pm 2 \circ \mathrm{O}$, $75 \circ \mathrm{O} \%$ $\mathrm{RH} \pm 5 \%$ in humidity control ovens ( ICH Q1A-Q1F 2003) After 60 days drug contents of all samples were determined by the method as in Drug content

During storage at different temperature and humidity conditions (room temperature as well as in stability chamber at $40 \pm 2^{\circ} \mathrm{C} / 75 \pm 5 \% \mathrm{RH}$ ), the optimized formulation was assayed at regular intervals of 15th, 30th, and 60th days. ${ }^{32}$

\section{RESULT AND DISCUSSION}

\section{Preformulation study}

\section{Physical State}

* Colour: A white or pale-yellow powder.

* Nature: Crystalline

* Odour: Practically Odorless.

\section{Melting Point}

The melting point of the Prochlorperazine maleate was determined by the capillary fusion method. A capillary was sealed at one end filled with a small amount of Prochlorperazine maleate and the capillary was kept inverted i.e., sealed end downwards into the melting point apparatus. The melting point was found to be $226^{\circ} \mathrm{C}$ $228^{\circ} \mathrm{C}$.

\section{Solubility}

Prochlorperazine maleate is very slightly soluble in distilled water $(0.002 \pm 0.01)$ and soluble in ethanol $(0.231 \pm 0.023)$.

\section{Calibration Curve For Prochlorperazine maleate}

The data for the calibration curve of Prochlorperazine Maleate is given in (table 2).

Table 2: Data for calibration curve of Prochlorperazine Maleate

\begin{tabular}{|c|c|}
\hline Concentration $\mu \mathrm{g} / \mathrm{ml}$ & Absorbance \\
\hline 5 & 0.1193 \\
\hline 10 & 0.2438 \\
\hline 15 & 0.3546 \\
\hline 20 & 0.4781 \\
\hline 25 & 0.5987 \\
\hline 30 & 0.7145 \\
\hline
\end{tabular}

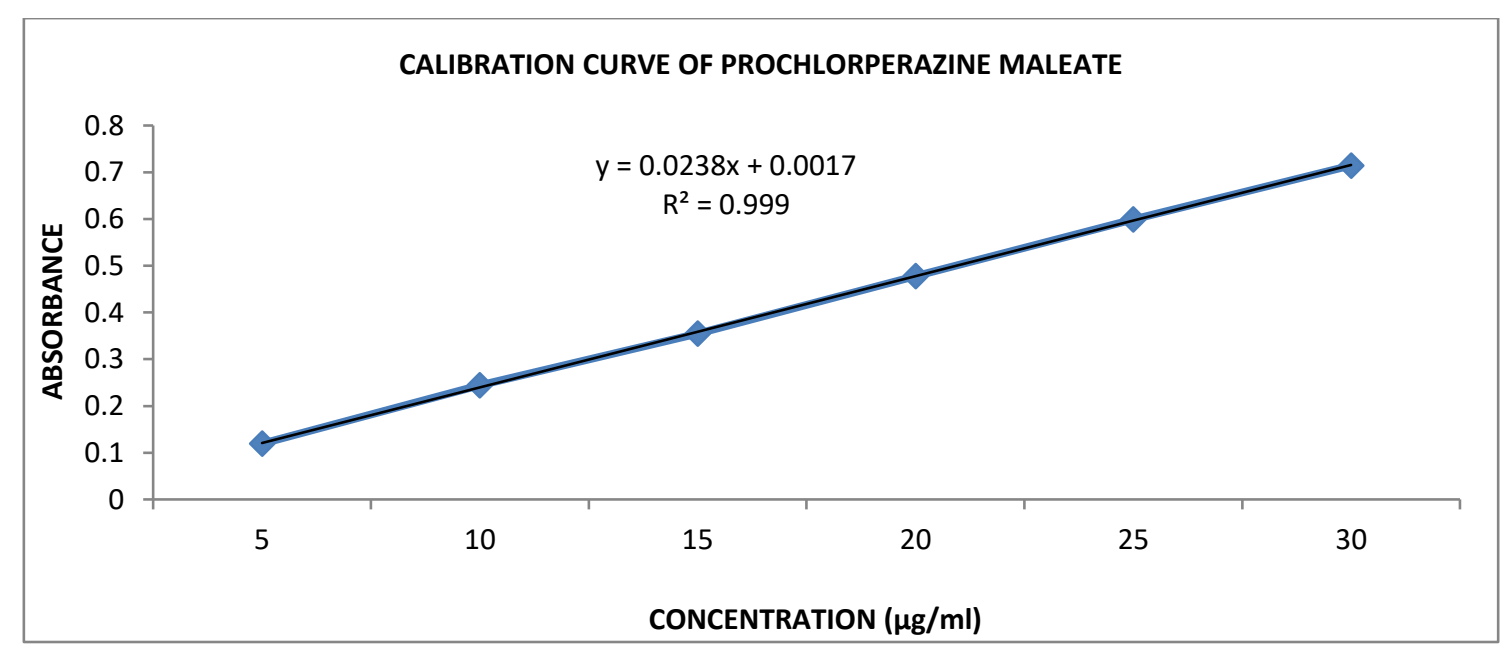

Figure 1: Calibration curve of Prochlorperazine Maleate 
It was found that the solutions of Prochlorperazine maleate in $0.1 \mathrm{~N} \mathrm{HCl}$ show linearity $\left(\mathrm{R}^{2}=0.999\right)$ (Fig. 1$)$ in absorbance at concentrations of $5-30 \mu \mathrm{g} / \mathrm{ml}$ and obey Beer Lambert's Law.

\section{Compatibility study}

The possible interactions between the drug and the excipients used in the formulation were studied by FTIR spectroscopy. The results are given below.

\section{FT-IR study}

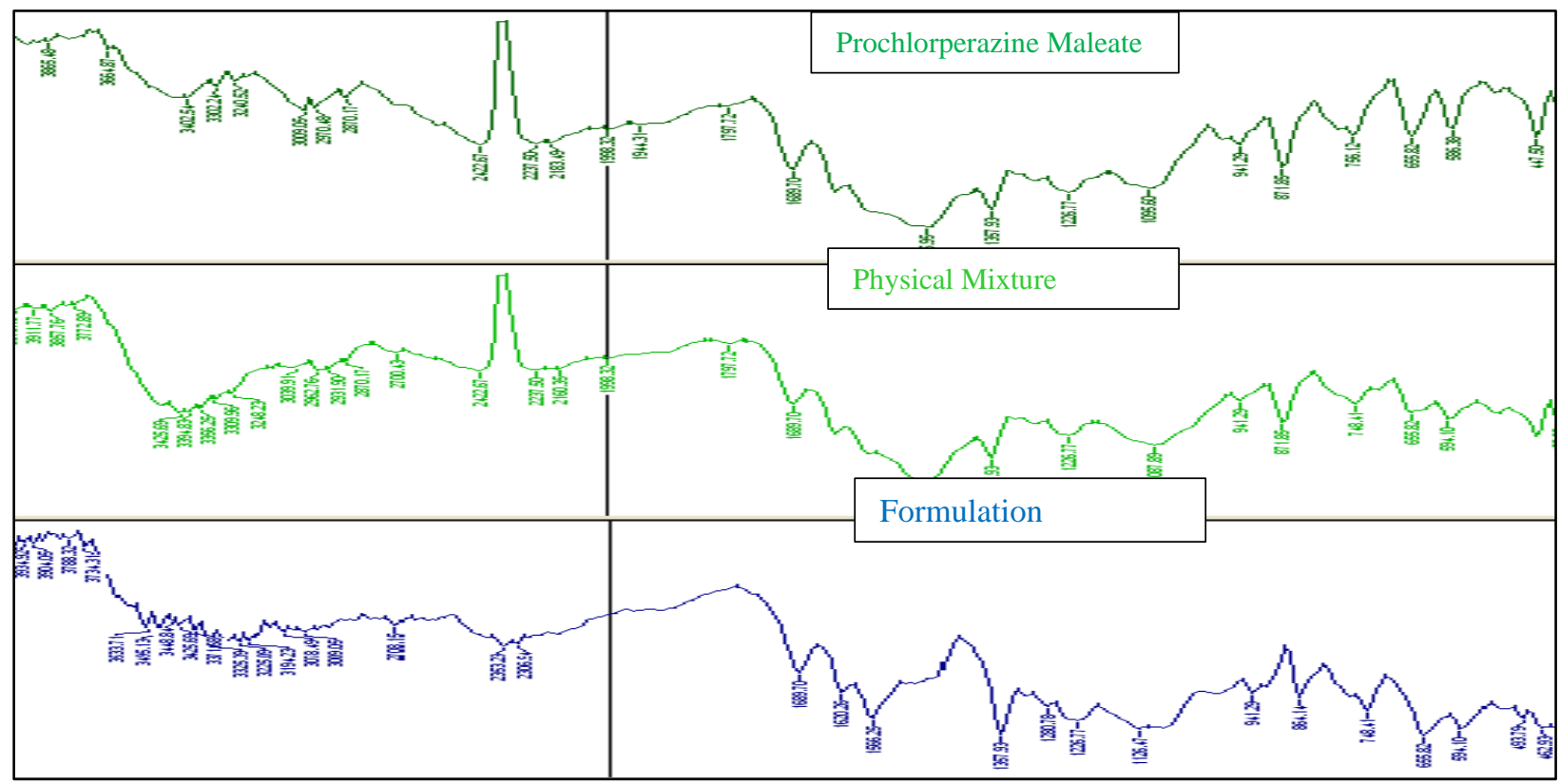

Figure 2: FT-IR spectra of prochlorperazine maleate, Physical Mixture, Formulation

Table 3: FT-IR spectral observed and standard values

\begin{tabular}{|c|c|c|c|}
\hline Sr. no & Probable function groups & Standard IR values $\mathbf{( c m}^{-\mathbf{1})}$ & Observed IR values $\left.\mathbf{( c m}^{-\mathbf{1}}\right)$ \\
\hline 1 & Hydroxyl $(\mathrm{OH})$ & $3100-3700$ & 3402.54 \\
\hline 2 & Ar. C-H from CH3 & $3100-3000$ & 3009.05 \\
\hline 3 & $\mathrm{C}-\mathrm{H})$ of aliphatic groups $\mathrm{CH}_{3}$ and $\mathrm{CH}_{2}$ & $3000-2840$ & 2970.48 \\
\hline 4 & Ar. C-Cl & $885-550$ & 871 \\
\hline 5 & $\mathrm{C}=\mathrm{O}$ & $1710-1680$ & 1689.70 \\
\hline 6 & Ar. C=C & $1670-1600$ & 1638.47 \\
\hline
\end{tabular}

The Fourier transform infrared spectroscopy (FTIR) spectrum for the pure Prochlorperazine maleate as shown in fig. 2. The displayed band at $3402.54 \mathrm{~cm}^{-1}$ attributed to the hydroxyl $(\mathrm{OH})$ in the maleate group, while the band $3009 \mathrm{~cm}^{-1}$ assigned to the $(\mathrm{C}-\mathrm{H})$ aromatic rings in the backbone of the prochlorperazine. The $(\mathrm{C}-\mathrm{H})$ of aliphatic groups $\left(\mathrm{CH}_{3}\right.$ and $\left.\mathrm{CH}_{2}\right)$ appeared in the expected area for the stretching vibration at $2970.48 \mathrm{~cm}^{-1}$. The bands appeared at $1689.70 \mathrm{~cm}^{-1}$ attributed to the $(\mathrm{C}=0)$ stretching of two carboxylic groups of maleate structure. The band appeared at $1638.47 \mathrm{~cm}^{-1}$ attributed to $(C=C)$ of the aromatic ring. The band appeared at $871 \mathrm{~cm}^{-1}(\mathrm{C}-\mathrm{Cl})$ stretching in the benzene ring. While the fingerprint area showed the bending bands of the drug.

The FTIR spectrum of Prochlorperazine maleate after formulation in floating beads forms as shown in Fig. 2 displayed the same functional group's band with small shifting indicating the compatibility and uniformity of excipients with the drug without any chemical modification of the drug. 


\section{Differential Scanning Calorimetry (DSC)}

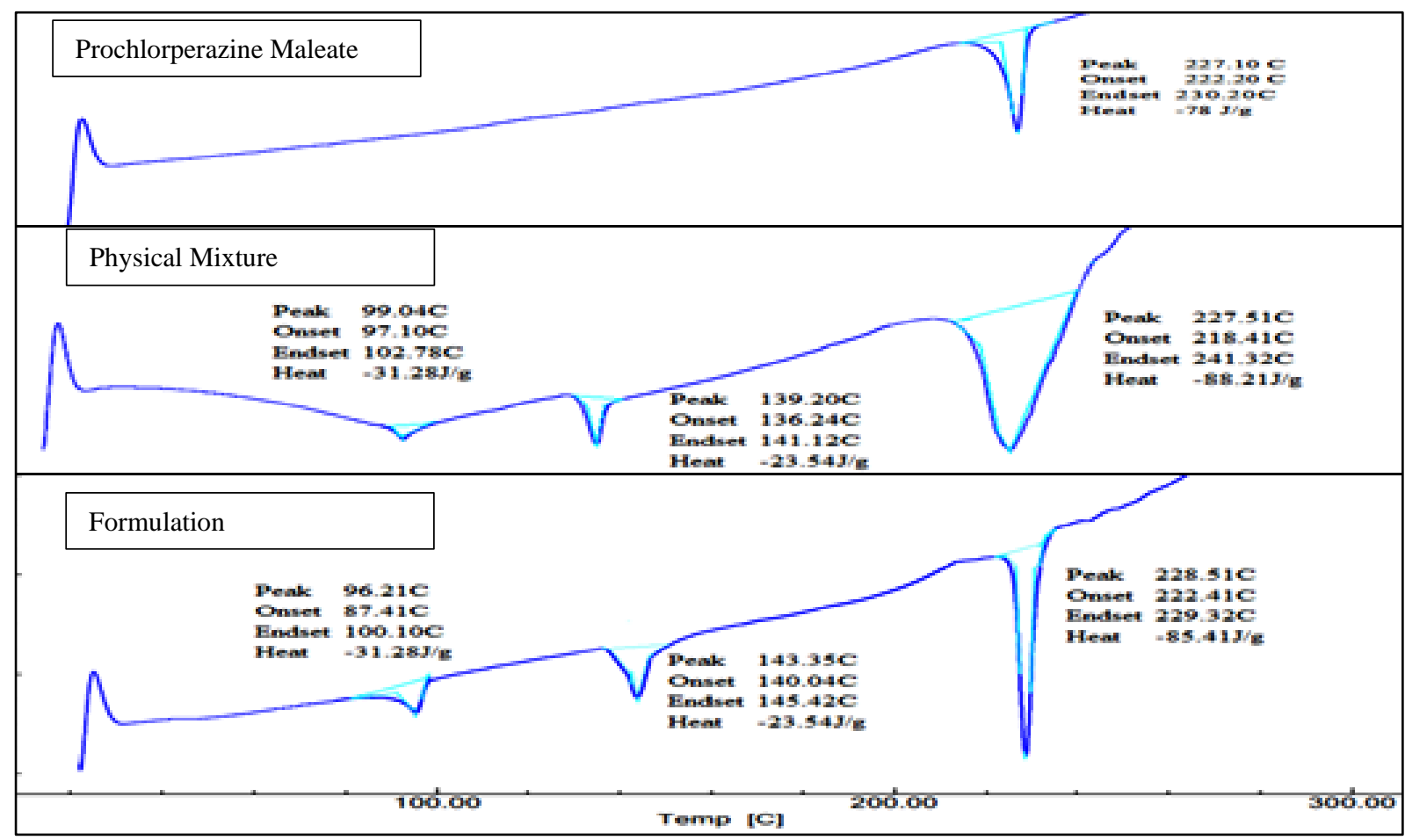

Figure 3: DSC Spectrum of Prochlorperazine Maleate, Physical Mixture and Formulation

The DSC analysis of pure Prochlorperazine maleate showed a characteristic, sharp endothermic peak at $222.41^{\circ} \mathrm{C}-228.51^{\circ} \mathrm{C}$ corresponding to its melting point and indicates the crystalline nature of the drug. The DSC analysis of the physical mixture of drug and excipients revealed a negligible change in the melting point of prochlorperazine maleate in the presence of excipients, indicating no modification or interaction between the drug and excipients shown in Fig. 3.

\section{Flow properties}

The angle of repose shows the good flow property of floating beads showed in (table 4). The B-2 formulation shows the excellent flow of the Beads also the Tapped Density, Hausner's ratio. Carr's index, within the excellent range, so that the prepared formulation is in complies with all flow properties.

\begin{tabular}{|l|c|c|c|c|c|c|c|c|}
\hline \multicolumn{1}{|c|}{ Formulation No. } & B-1 & B-2 & B-3 & B-4 & B-5 & B-6 & B-7 & B-8 \\
\hline Angle of repose & 32.89 & 28.55 & 32.88 & 32.49 & 26.65 & 31.41 & 31.88 & 30.54 \\
\hline Tapped Density & 0.466 & 0.472 & 0.478 & 0.408 & 0.471 & 0.504 & 0.527 & 0.489 \\
\hline Hausner's Ratio & 1.14 & 1.15 & 1.12 & 1.11 & 1.14 & 1.13 & 1.16 & 1.14 \\
\hline Compressibility Index & 12.56 & 14.12 & 12.56 & 11.28 & 10.46 & 12.94 & 12.38 & 12.48 \\
\hline Bulk Density (g/ml) & 0.524 & 0.436 & 0.465 & 0.471 & 0.512 & 0.502 & 0.531 & 0.529 \\
\hline
\end{tabular}

The bulk densities of various Prochlorperazine maleate floating beads formulations were found to be within the range $(0.436-0.531 \mathrm{~g} / \mathrm{ml}$ ) as shown in (table 4$)$. The density of all formulations found that less than the density of 0.1 $\mathrm{N} \mathrm{HCl}(1.004 \mathrm{~g} / \mathrm{ml})$. So that, the floating alginate beads are float in $0.1 \mathrm{~N} \mathrm{HCl}$.

\section{Characterization of Enclosed Prochlorperazine Maleate Floating Alginate Beads}

\section{Percentage yield}

The Percentage yield of Prochlorperazine maleate Beads of formulated batches was found to be $86.29 \%$ to $95.90 \%$. Present investigation it was found that the polymer, co- polymer concentration, and crosslinking agent concentration was not more effect on percentage yield. The B-2 batch gives the highest result it was found to be $95.90 \%$.

\section{Drug content and drug entrapment efficiency}

The drug content of different batches B-1 to B- 8 was found to be $3.7 \mathrm{mg}$ to $4.7 \mathrm{mg}$. The percentage of Entrapment Efficiency was found to be $74 \%$ to $94 \%$. The B-2 batch showed the best result than other batches. The present study was concluded that the increase in the polymer and co-polymer concentration will increase the entrapment efficiency. 
In-vitro buoyancy study

Table 5: In-vitro \% buoyancy study of batches B-1 to B-8.

\begin{tabular}{|c|c|c|c|}
\hline Formulation no. & Floating lag time (seconds) & Floating time (h) & Percentage Buoyancy (\%) \\
\hline B 1 & 30 & $>12 \mathrm{~h}$ & 93.33 \\
\hline B 2 & 10 & $>12 \mathrm{~h}$ & 97.50 \\
\hline B 3 & 37 & $>12 \mathrm{~h}$ & 91.40 \\
\hline B 4 & 23 & $>12 \mathrm{~h}$ & 89.50 \\
\hline B 5 & 25 & $>12 \mathrm{~h}$ & 95.26 \\
\hline B 6 & 13 & $>12 \mathrm{~h}$ & 92.00 \\
\hline B 7 & 17 & $>12 \mathrm{~h}$ & 89.40 \\
\hline B 8 & 26 & $>12 \mathrm{~h}$ & 94.80 \\
\hline
\end{tabular}

All the batches had floating time greater than $12 \mathrm{~h}$. Thus, had very little floating lag time (10 to $37 \mathrm{sec}$ ) as given in (table 5). This is due to the low relative density of Sodium Alginate and Pectin which helped the beads to become buoyant. The percentage buoyancy was found to be In-vitro drug release study
$89.40 \%$ to $97.50 \%$ of Batch B-1 to B-8. it was found that varying the polymer and copolymer concentration in the beads formulation will normally effect on floating lag time and buoyancy time of the beads in dissolution media. The formulation B-2 gives optimum buoyancy up to $97.50 \%$.

Table 6: in-vitro drug release study of $\mathrm{FAB}$

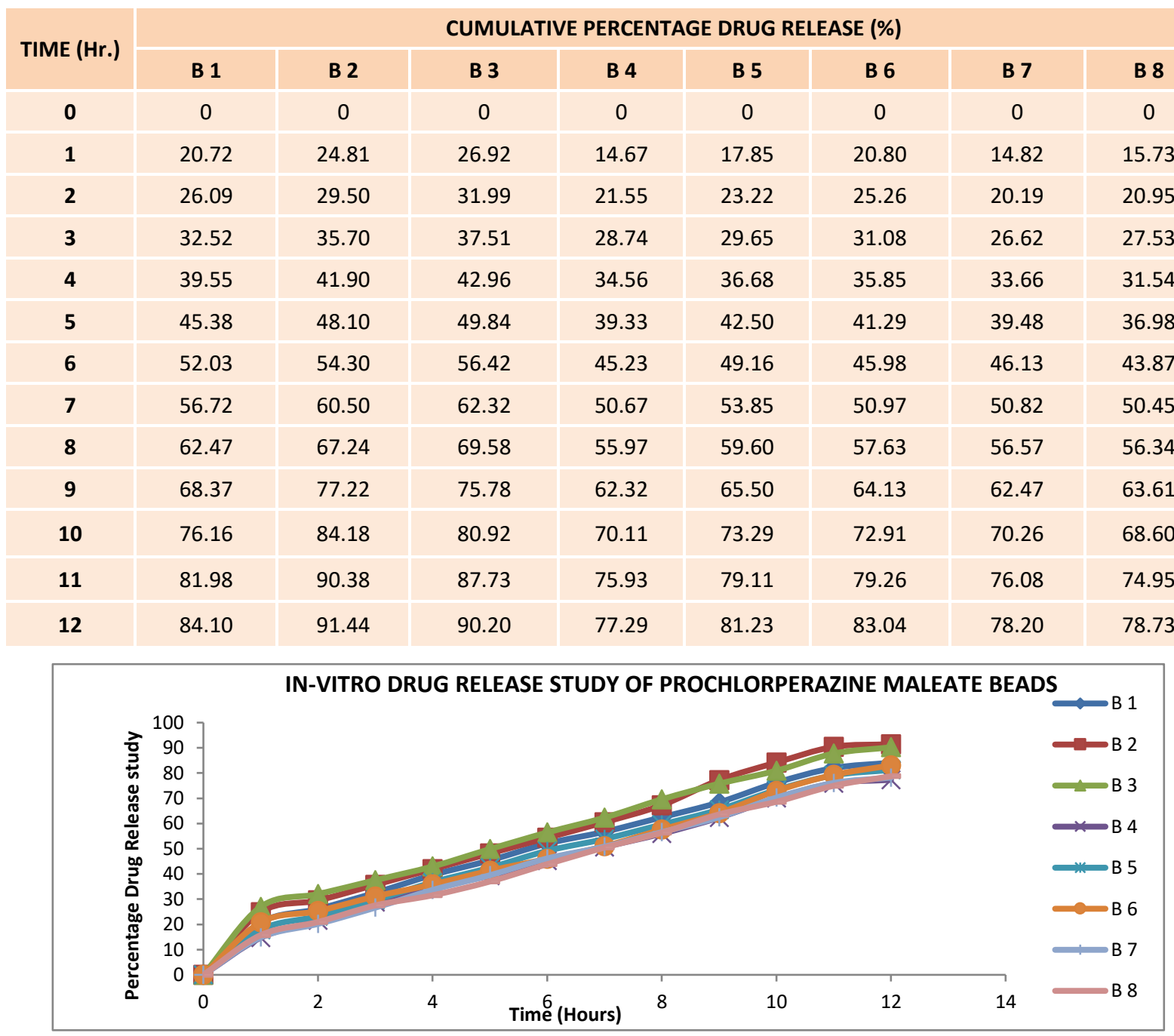

Figure 4: In-vitro drug release study of FAB of batches B-1 to B-8 
The in-vitro drug release study of batch B-1 to B-8 was carried out and the percentage of drug release from the FAB ranged from $77.29 \%$ to $91.44 \%$ at the end of $12 \mathrm{~h}$ shown in (Table 6). The results showed that the drug release pattern was affected by polymer concentration, the ratio of drug-polymer mixture, and the concentration of the crosslinking agent.

\section{The Selection of Best Formulation}

The best formulation was selected as batch B-2 which gives the best result based on Percentage Yield, Drug content, Buoyancy Study, and in-vitro Drug Released study.

\section{Size analysis}

The particle size of the optimized B-2 batch results measurement of the mean particle size of the optimized formulation (Batch: B-2) of the floating alginate beads was found to be $393.3 \mathrm{~nm}$. The particle size of the Alginate beads was found to be in the nano range. This is because the viscosity of the formulation is optimum, which in turn reduces the interfacial tension, and finally increases the stirring efficiency, which results in reduced particle size. The present study indicated that there was not any remarkable effect of concentration of excipients on the particle size of prepared Alginate beads.

\section{Zeta potential}

Zeta potential of optimized formulation (Batch: B2) of the floating beads was found to be $-2.84 \mathrm{mV}$. The results showed good zeta potential. This result evident that the interaction between the polymers: Alginate and Pectin may impact the Zeta potential. Choosing a sufficient amount of alginate in comparison with the amount of Pectin can cause electrostatic repulsion between floating beads to provide enough surface charges for stabilization of the formulation.

\section{Morphology study by Scanning Electron Microscopy (SEM)}

SEM photomicrograph of drug-loaded Floating Alginate beads optimized batch B-2 was showed Spherical and the external surface was slightly rough/ shrinkage which could be drying. The SEM photomicrograph of the structure of the entire bead under $500 \mu \mathrm{m}$ views of the Floating beads of optimized formulation show in Figure No.5 reveals that pores and channels are distributed throughout the surface. Present investigation indicates that there were no significant effects of variables on the surface morphology of alginate beads.

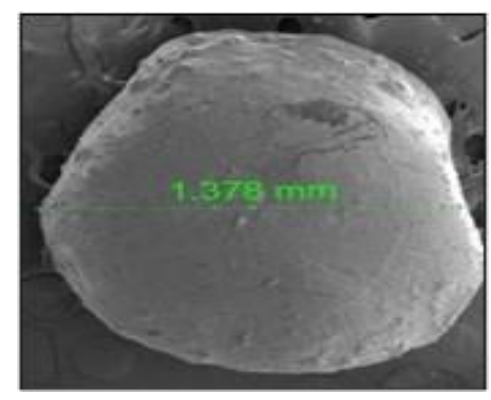

Figure 5: SEM Photomicrograph of optimized batch B-2

\section{Powder- XRD}

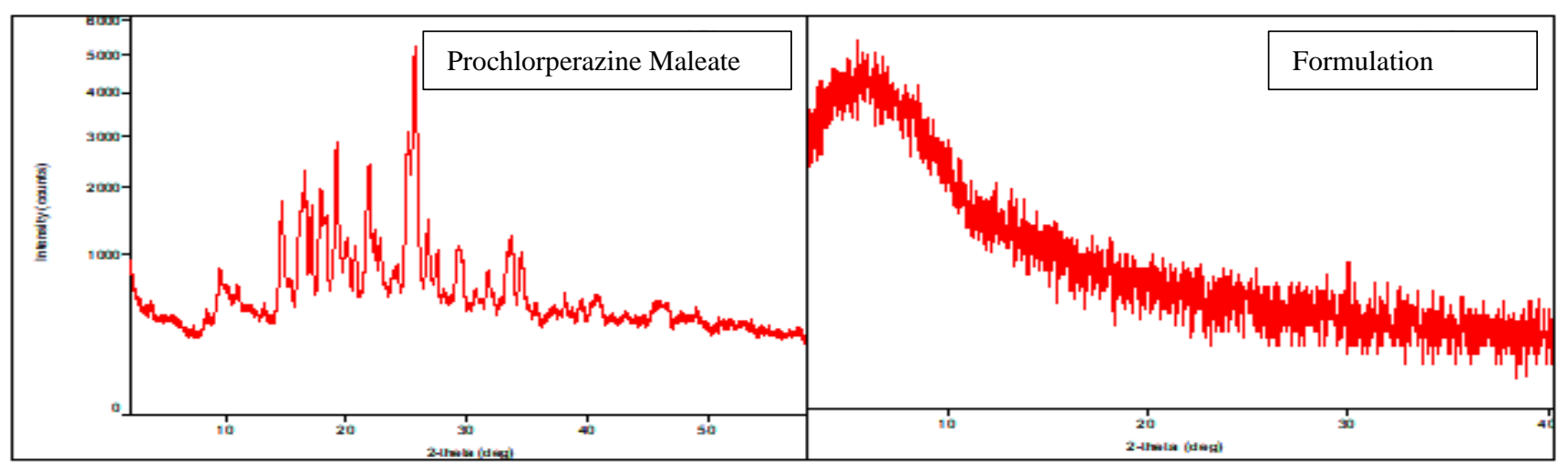

Figure 6: PXRD of Optimized B-2 Floating Alginate Beads Formulation

Powder XRD of Prochlorperazine Maleate and formulation was recorded using Rigaku diffractometer. The prochlorperazine maleate showed intense peaks or sharp peaks described multi-crystalline patterns in Fig. 6. However, the prochlorperazine maleate enclosed floating alginate beads showed diminished or less intense peaks in Fig. 6, revealing that the prochlorperazine maleate was get converted into an amorphous form.

\section{Stability studies}

Throughout the time of storage at different temperature and humidity conditions (room temperature as well as in stability chamber at $\left.40 \pm 2^{\circ} \mathrm{C} / 75 \pm 5 \% \mathrm{RH}\right)$, the optimized formulation B 2 was assayed at regular intervals of 15th, 30th, and 60th days. The B 2 Optimized batch drug content was found to be $4.62 \mathrm{mg}$ and it is having no change in its physical appearance. Hence it shows good stability up to $60^{\text {th }}$ day.

\section{CONCLUSION}

The present study reports the development of floating alginate beads for sustained release of Prochlorperazine maleate following oral administration. This was successfully prepared by the lonotropic gelation method 
which can be taken once daily having an advantage over immediate release dosage form which required 3-4 times administration daily. Thus, once a day formulation results in improved bioavailability and thereby patient compliance. The result demonstrated that the release of the drug is dependent on the different ratios of hydrophilic polymers Sodium Alginate and Pectin. It can be conclusively stated that the B-2 formulation appears to be a promising system for the sustained release of Prochlorperazine maleate for Anti-emetic therapy based on actual percentage yield, Drug content, Percentage buoyancy study, and in-vitro drug release data. From the results, it was also concluded that the release rate of the drug is slow and consistent in polymer ratio of 1:1 than other formulations.

Acknowledgement: The authors are thankful to Harika Drugs PVT. LTD (Hyderabad) for providing a gift sample of Prochlorperazine Maleate.

\section{REFERENCES}

1. Shah S, Pandya S. International journal of Pharmaceutical Sciences and Research. 2010; 1(6): 7-18.

2. Arora S, Ali J, Ahuja A, Khar R, Baboota S. Floating Drug Delivery Systems: A Review. American Association of Pharmaceutical Scientists. 2005; 6(3): 373-90.

3. Avaru G, Pratusha A, Morsu A. Formulation and Evaluation of Gastro Retentive Drug Delivery System of Tizanidine Hydrochloride: A Review. International Research Journal of Pharmacy. 2014; 3(10): 34-45.

4. Jain S. K, Awasthi A. M, Jain N. K, Agrawal G. P. Calcium silicate based microspheres of repaglinide for gastroretentive floating drug delivery: Preparation and in vitro characterization. Journal of Control Release. 2005; 107(2): 300-9.

5. Garg R, Gupta G. D. Progress in Controlled Gastroretentive Delivery Systems. Tropical Journal of Pharmaceutical Research, 2008; 7(3): 1055-1066.

6. Mahale G. S, Derle N. D, Floating drug delivery system:A novel approach. Journal of Pharmaceutical and Scientific Innovation. 2012; 1(4): 1-6.

7. Kumar R, Kamboj S, Chandra A, Gautam P. K, Sharma V. K. Microballoons: An Advance Avenue for Gastroretentive Drug Delivery System- A Review. UK Journal of Pharmaceutical Biosciences. 2016; 4(4): 29.

8. Hung S. C, Haeggy K, Peggy K, Joseph R. A. Bioadhesive polymers as platforms for oral controlled drug delivery II: Synthesis and evaluation of some swelling, water-insoluble bioadhesive polymers. Journal of Pharmceutical Science. 1985; 74(4): 399-405.

9. Yie W. Chein et al. Second edition. Iondon; 2014. 149-151.

10. Patil P, Chavanke D, Wagh M. A review on ionotropic gelation method: novel approach for controlled. International Journal of Pharmacy and Pharmaceutical Sciences.2012; 4(4): 27-32.

11. Dhole A. R, Gaikwad P. D, Bankar V. H, Pawar S. P. A Review On Floating Multiparticulate Drug Delivery System - A Novel Approaches To Gastric Retention. 2011;6(2):205-211.
12. DrugBank.ca. 'Prochlorperazine Maleate' Available https://www.drugbank.ca/drugs/ DB00433\#referenceL6643.

13. Indian Pharmacopoeia. Vol. 3. Ministry of Health and Family Welfare. Ghaziabad, India: The Indian Pharmacopoeia commission. 2007.

14. Deb J. Venkateswarlu B.S., Ghosh A., Choudhuri T., Paul $P$, Faizi M. Formulation and evaluation of carbopol Microspheres of metformin $\mathrm{HCl}$. Asian Journal of Biomedical and Pharmaceutical Sciences 2011; 1(2)1119.

15. Chatwal G. R, Anand S. K. Instrumental methods of Chemical Analysis. Himalaya Publishing House, Mumbai. $2011 ; 2.44$.

16. United States Pharmacopoeia, 30th edition NF 25-2007. The Official Compendia of Standards. 643, Pharmacopoeial forum 32(1): 141.

17. Indian Pharmacopoeia, Ministry of Health and Family Welfare. Ghaziabad, India: The Indian Pharmacopoeia commission. 2014.

18. Pawashe P. M., Kumar S. S, Naikwade Nilofar S. Prochlorperazine Maleate Loaded Sustained Release Floating Microspheres Prepared By lonotropic Gelation Technique: Morphology And Release Characterstics. Research Journal of Pharmacy and Technology. 2019; 12(8): 3866-3872.

19. Almajidi Y. Q, Albaderi A. A, Fadhel H. Enhance Solubility And Prolong Release Of Prochlorperazine Maleate Using Floating Nanoemulsion In Situ Gel. Asian Journal of Pharmaceutical and Clinical Research. 2019; 12(1): 1-5.

20. Olubunmi J. Olayemi, Yonni E. Apeji, Christianah Y. Isimi. Formulation and evaluation of cyperus esculentus (Tiger nut) Starch-Alginate Microbeads in the oral Delivery of Ibuprofen. Journal of Pharmaceutical Innovation. 2020.

21. A. H. Beckett, J.B Stenlake. Practical Pharmaceutical Chemistry, Fourth Edition.CBS publishers and Distributors pvt Itd. Page no. 281.

22. Nimase P. K., G. Vidyasagae. Preparation and evaluation OF floating calcium alginate beads of clarithromycine. Der Pharmacia sinica. 2010; 1(1): 29-35.

23. Mowafaq M. G, Zainab A R. Formulation and in-vitro evaluation of Trimetazidine dihydrochloride. International Journal of Pharmacy and Pharmaceutical Sciences. 2014; 6(2): 456-460.

24. Jaiswal D, Bhattacharya A, Yadav I, Singh H, Chandra D. A. Formulation and Evaluation of oil entrapped floating alginate beads of Ranitidine hydrochloride. International Journal of Pharmacy and Pharmaceutical sciences. 2009; 1(1): 128-140.

25. Barito R, M, B Ajay. Nagendra N. Audinarayana, Reddy K, $B$, Mohanambal E. Formulation and Evaluation of Lamivudine enclosed alginate microbeads. 2011; 3(6).

26. Dash S, Murthy P, N, Nath L, Chowdhary P. Kinetic modeling on drug release from controlled drug delivery systems. Acta Poloniae Pharmaceutica Drug research. 2010; 67(3): 217-223.

27. Malakar J, Prabir K. D, Purakayastha S. D, Nayak S. D. 
Floating capsules containing alginate-based beads of Salbutamol sulfate: in-vitro and in- vivo evaluations. International Journal of Biological Macromolecules. 2014; 64: 181-189.

28. Sherina V. M, Santhi K., Sajeeth C. I. Formulation and Evaluation of Sodium Alginate Microbeads as a Carrier for the controlled release of Nifedipine. International Journal of Pharmaceutical and Chemical Sciences. 2012; 1(2): 699-706.

29. Rajpali D, Gupta V. Floating Microspheres Based Nizatidine Gastro Retentive Formulation to Control the Release of Drug. Letters in Applied Nano Bio Science. 2020; 9(3): 1409-1419.
30. Arifa S. K, Jhansi J, Padmalatha K. Formulation and Evaluation of Floating Gel Beads of Loratadine. International journal of pharmaceutical sciences and research. 2019; 10(3): 1289-1299.

31. Katta R, Deveswaran R, Bharath S, Basavaraj B. V. development of mesalazine Microspheres for colon target. In international journal of applied pharmaceutics. 2014 0975-7058.

32. Patil A, Pawar P, Gharge V, Doltade U, Doijad R. Mesalamine-loaded mucoadhesive Microsphere for colon drug delivery system: Effect of process variables and in-vitro characterization International Journal of Pharmaceutical Investigation. 2019; 8(2): 5625-5628.

Source of Support: The author(s) received no financial support for the research, authorship, and/or publication of this article.

Conflict of Interest: The author(s) declared no potential conflicts of interest with respect to the research, authorship, and/or publication of this article.

For any question relates to this article, please reach us at: editor@globalresearchonline.net New manuscripts for publication can be submitted at: submit@globalresearchonline.net and submit_ijpsrr@rediffmail.com 